\title{
THE MANY CONTEXTS OF TRANSLATION (STUDIES)
}

\author{
RODICA DIMITRIU \\ Alexandru Ioan Cuza University of Iaşi
}

\begin{abstract}
This article examines the ways in which, in just a couple of decades, and in view of the interdisciplinary nature of Translation Studies, the key notion of context has become increasingly broader and diversified within this area of research, allowing for complex analyses of the translators' activities and decisions, of translation processes and, ultimately, of what accounts for the meaning(s) of a translated text. Consequently, some (brief) incursions are made into a number of (main) directions of the discipline and the related kinds of contexts they prioritized in investigating translation both as process and product. In the second section of this introductory article, the issue of context is particularized through references to the contributions in this special volume, which add new layers of meaning to context, touching upon further perspectives from which this complex notion could be approached.
\end{abstract}

Keywords: context, co-text, linguistic directions in Translation Studies, pragmatic directions, socio-cultural directions

In the last couple of decades, "context" has become an increasingly important parameter according to which research is carried out in almost every field of knowledge. In the linguistic and pragmatic as well as in the cultural and literary studies it has turned into a main area of investigation, which is tightly related to the creation and interpretation of meaning(s). However, this complex notion has been taken into account even by the more traditional (linguistic and literary) philosophical and philological discourse, ${ }^{1}$ whenever processes of retrieving meaning at various levels and/or of providing various forms of textual interpretation were involved. What has varied and changed over time, though, have been the different semantic boundaries that have been assigned to context, in keeping with its occasional association to other related notions - situation of communication, situational context, co-text, etc. - and with the various disciplines that have made use of it.

\footnotetext{
${ }^{1}$ In “Text and Context in Translation", Juliane House mentions philosophy, psychology, pragmatics, sociolinguistics/anthropology and functional linguistics.
} 
On the other hand, and in spite of the occasionally diverging acceptations of the term, scholars from different fields of research have agreed that, over the last 50 years or so, there has been a clear tendency towards broadening and diversifying the meaning of context itself as well as towards increasing its importance until it has come to gain supremacy in deconstructionist approaches. In Margins of Philosophy (1984) Derrida insists that there are no longer stable meaning cores (deep structures), but "only contexts without any center of absolute anchoring" (320). Hence the constant need for contextualization and recontextualisation.

Perhaps no other discipline could better illustrate the multitude of contexts that have been used, and their importance for various kinds of investigations, than Translation Studies. Even outside a deconstructionist framework of discussion, in view of its interdisciplinary nature, Translation Studies has resorted to methodologies - and related contexts - associated to such diverse areas of research as linguistics and pragmatics, cultural and literary studies as well as sociology - among many others.

One of the aims of this (introductory) article is precisely to capture - in a more or less chronological order - the increasingly broad contexts Translation Studies has operated with through the years, a tendency which has coincided with a series of developments in the discipline. The analyses will entail a number of incursions into some of the main directions in Translation Studies, with due attention being paid to the methodological consequences of contextual investigations in terms of refining on-going research in the field.

A final section of this general, state-of-the art kind of presentation will, in a sense, particularize the whole issue of context through references to contributions in this volume which add new layers of meaning to this complex notion, touching upon further perspectives from which context could be approached.

\section{Context in Linguistics-Oriented Approaches}

Discussions of context in the "modern" linguistics-oriented direction in Translation Studies started to emerge in the wake of the unprecedented development of linguistics, after WWII. As is well known, in the first decades after the war, translation was regarded as a branch of applied linguistics and was taken into consideration (both as a tool of investigation and an objective in itself) by contrastive studies and comparative stylistics. The key notion of translation unit that was used in the linguistic approaches to translation, and mainly covered the word and sentence levels, could well be related to the dimensions of context itself, which frequently did not exceed the sentence level. Thus, the meaning of a polysemantic word could be disambiguated by its context or, as J. C. Catford expressed this idea back in the 1960's, "The SL and TL items rarely have the same meaning in the linguistic sense; but they can function in the same 
situation" (A Linguistic 49). Eugene A. Nida, in whose theory of translation context plays a crucial part, started from a paradigmatic type of context for words, undertaking componential analyses of lexical items with related meanings (e. g. talk, whisper, babble, murmur, stutter, sing, hum). Very soon he became interested in the syntagmatic context, realizing that the conceptual level is actually a combination of words. In this respect, he followed Martin Joos claiming that "in determining the meaning of words the role of context is maximized and the role of any focal element is minimized, which means that the context actually provides more distinctiveness of meaning than the term being analysed" (Contexts 31). In Nida's view, "contexts represent the principal means by which most people learn the meanings of at least $95 \%$ of their active and passive vocabulary" (Contexts 35). This is why dictionaries - bilingual ones in particular - are regarded as unsatisfactory for professional translators, in spite of clear efforts, with more recently published dictionaries, to provide more context for each lexical entry. One famous set of examples through which Nida demonstrates how context disambiguates meaning concerns the verb to run, which includes among others, utterances such as: the boy is running; the horse is running; the snake is running on the lawn; the clock is running; his heart is running; the car is running - if we were to refer only to one basic meaning of this verb, that of 'rapid movement,' to which many others could be added (Contexts 32-33).

Collocations, also called recurrent or fixed combinations (BBI xv) are such examples of immediate syntagmatic context that may or may not involve similar word combinations in translation. For instance, the English-Romanian language pair, to take a picture has a divergent correspondent - a face o fotografie [Back translation: to make a picture]. The same could be said about to make a speech-a tine un discurs [Back translation: to hold a speech(?)], a strong tea - un ceai tare [Back translation: hard tea (?) rather than puternic - strong], but for the lexical collocations a weak tea - un ceai slab, or a difficult choice -o alegere dificilă calque is possible, etc. Disregarding the specificity of the immediate context of collocations has frequently resulted in clumsy, artificial, strange, inadequate translations, as translator trainers know but too well from their teaching experience.

However, even at word level, a number of scholars, e.g. Peter Newmark, have claimed that "some words are more context-dependent or bound than others" (About Translation 87), the least context-bound being specialized terms for which a one-to-one term-concept relationship is established. Still, terminologists with a translation-oriented perspective such as Schmitt have persuasively demonstrated that "terms and concepts are embedded in a system from which they derive their meaning" and that there are "cultural differences in such systems, even in the technical area" (in Rogers, "Translating Terms" 105). 
Beyond the word level of translation and the context(s) it triggers, in linguistic approaches the sentence has also been regarded as a satisfactory level for completing meaning and transferring it into another language. Candace Séguinot provides empirical evidence from translator videotapes that "[translators] read and comprehend a typographical sentence before they start, and they continue translating either until they encounter a problem or their memory fails" ("Translation Theory" 91). It is also at sentence level that, throughout the translation process, the translators may operate changes to their initial translation options. Before Séguinot, and also for mainly cognitive reasons, Newmark had supported the sentence as a unit of translation with a rounded off, complete meaning: "Since the sentence is the basic unit of thought, presenting an object and what it does, is, or is affected by, so the sentence is, in the first instance, your unit of translation, even though you may later find many SL and TL correspondences within that sentence" (A Textbook of Translation 31).

\section{Context in Pragmatics, Discourse Analysis and Critical Discourse Analysis}

The pragmatic approaches that had come to replace, in the 1980's, the 'strictly linguistic' ones, broadened to a considerable extent the contexts in which meaning was explored in Translation Studies. As pragmatics refers to "the study of meaning, not as generated by the linguistic system but as conveyed and manipulated by participants in a communicative situation" (Baker, In Other Words 217), from a mere operation of linguistic replacement, translation came to be regarded as "language in action", as a form of communication that requires the study of all those elements that have a bearing on (translated) oral or written discourses/texts. Consequently, there was a shift of emphasis, in Translation Studies as well, from the word and sentence (micro) levels of analysis to the (macro) textual one. In Neubert's words, "texts are building blocks of communication in general and of translation in particular" (Translation as Text 25). From this perspective, texts need to be approached in a top-down manner both in terms of analysis and in view of the translation proper: in this way textual features of meaning could better be examined before reaching the (lower) levels of sentences, phrases and words. The main (occasionally overlapping) concerns of pragmatic and discourse-oriented approaches in Translation Studies were, on the one hand, to describe texts themselves in terms of their characteristic features (Neubert and Shreve; Baker) and typology (e.g. Trosborg). On the other hand, scholars (e.g. House; Baker; Hatim and Mason, etc.) tried to enlarge the context of discussion beyond the strictly textual level in order to provide more accurate explanations of the way in which language communicates meaning as well as social and power relations. By adopting Halliday's model of discourse analysis based on his 'systemic functional 
grammar' translation scholars attempted to relate the translator's linguistic choices as materialised in the text to wider systemic frameworks/contexts of communication; thus, in their view, the sociocultural framework may condition genre; genre determines register the variables of which (field, tenor, mode of discourse) are associated to strands of meaning which define the discourse semantics of a text (ideational, interpersonal, textual); ultimately, discourse is concretized in its lexicogrammar (transitivity, modality, theme-rheme/cohesion):

Sociocultural context

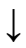

Genre

Register (field, tenor, mode)

Discourse semantics (ideational, interpersonal, textual)

Lexicogrammar (transitivity, modality, theme-rheme/cohesion)

(Relation of genre and register to language, cf. Munday,Introducing Translation Studies 90)

A more recent development of discourse analysis that has also been researched in Translation Studies is Critical Discourse Analysis (CDA), drawing on studies by Norman Fairclough, Teun A. van Dijk, etc. - and completed as well as applied to Translation Studies by scholars such as Jeremy Munday, Hatim and Mason, Christina Schäffner, etc.). ${ }^{2}$ The purpose of CDA is, in Munday's words, to show "how ideology is conveyed and presented textually in translation" $(2008,196)$. Methodologically, CDA frequently makes use of a set of linguistic analytical tools, adopted from Halliday's functional grammar in order to reveal how language can be used to manipulate readers' responses. In a comprehensive study on "Translation and Ideology," to which the subtitle "A Textual Approach"is significantly added, Munday reviews a number of insights from this discipline noticing that "the translator's linguistic perspective will inevitably

\footnotetext{
${ }^{2}$ Some people make a (chronological) distinction between critical linguistics (Hodge and Cress, Fowler) and CDA, although their objectives are roughly the same.
} 
differ from the author's. In addition to the presence of two different language systems, more subtly the translator's individual experience of language through education, the media and the local environment will mean that his or her "lexical priming will be unique, and therefore will have an important bearing on the phraseology and functional patterns of the translated text" (199, my emphasis). The important notion of "lexical priming" belongs to Hoey (Lexical Priming 8), and it refers to the way a word "becomes cumulatively loaded with the contexts and co-texts in which it is encountered." It serves as yet another explanation for the dissimilarity between translations of the same text and, more precisely, for the (sometimes unintended) ideological interpretations particular translation solutions may lead to.

In all the linguistic and pragmatic directions discussed so far, the notion of context that assists meaning interpretation has concerned the strictly linguistic environment of a word, phrase, sentence or text. It has followed one of the main definitions of the term that may be found not only in dictionaries of linguistics, but also in monolingual English dictionaries of everyday use, ${ }^{3}$ i.e. "the parts of a piece of writing, speech, etc., that precede and follow a word or passage and contribute to its full meaning" (Collins Dictionary). This (linguistic) meaning of context has sometimes been referred to as co-text (a term first suggested by Catford), and defined as "the linguistic environment in which a word is used within a text." ${ }^{4}$ Even if pragmatics and discourse analysis have broadened linguistic contexts, incorporating a semiotic dimension in Hatim and Mason's research, the scholars' investigations are ultimately carried out at the textual level, which is the only one used to provide evidence for particular interpretations of (translated) meaning.

\section{Context in Functionalist Approaches}

However, the 1980's and the 1990's saw yet another shift of paradigm in Translation Studies with the emergence, in Germany, of the functionalist direction of research, which incorporates Hans Vermeer's skopos theory, Katharina Reiss's studies in text functions and text typology, Justa Holz Mänttäri's theory of translatorial action as well as Christiane Nord's translation model drawing on previous research. From a context-related perspective, it should be noted that all these scholars were prepared to accept and anayse (it is true, in different proportions with each particular scholar) broader extratextual contexts that had a bearing on translation both as process and product. This stance thus marked a departure from "[the] rather formal translation theories,

\footnotetext{
${ }^{3}$ In some widely popular monolingual dictionary (e.g. Collins Dictionary, Chambers Dictionary, Free Dictionary, Dictionary Reference, etc.) it is the "linguistic" acceptation of the term that comes first in the dictionary entry.

${ }^{4} \mathrm{http}: / / w w w . b i b l e . g e n . n z /$ amos/language/cotext.htm
} 
firmly situated within the framework of applied and comparative linguistics, to a more functionally and socioculturally oriented concept of translation" (Schäffner "Functionalist Approaches" 116). This sociocultural dimension spreads from a new perspective on translation, which is no longer regarded as a code-switching operation, but as a specific form of human action that, like any other human action, is purpose-oriented.

In Hans Vermeer's skopos theory, it is the translation purpose, as formulated by the client/commissioner in the translation instructions - therefore in an extratextual situation of communication - that will guide the translator's decisions and justify the function of the final product in the target culture. As Mary Snell-Hornby notices, to Vermeer translation is, first and foremost, "a cultural transfer rather than a linguistic one, language being part of culture" (The Turns of Translation Studies 54). The book that Vermeer wrote together with Katharina Reiss, Towards a General Theory of Translatorial Action (1984/2013) sets the basis for an approach that relativizes translation through its dependency on the skopos and, in keeping with Reiss's correlations between function, text and translation method, is applicable to both literary and non-literary texts.

Justa Holz Mänttäri's theory of translatorial action, also elaborated in 1984 (Translatorisches Handeln / Translatorial Action), moves the translation operation even further from its strictly linguistic/textual context. In $\mathrm{Holz}$ Mänttäri's view, translation functions in a professional setting of intercultural communication. This theory is informed by communication theory and by action theory: the former enables the researcher to highlight the components involved in a process of communication across cultural barriers, while action theory provides the basis for a delineation of the specific characteristics of translatorial action (cf. Schäffner 118).

Perhaps the scholar who has best managed to strike the most equitable balance between linguistic and extralinguistic contexts of investigation in functionalist approaches has been Christiane Nord (Text Analysis in Translation). Her approach, that has a strong didactic dimension, enlarges and completes previous functional research (Jakobson, Reiss, Vermeer, House), and comprises, among other things, a taxonomy of translation functions and a tripartite model. Thus, a prospective or retrospective/i.e. evaluative translation analysis, includes: 1) the examination of the translation instructions/brief, 2) the ST analysis as well as 3) a classification and hierarchization of translation problems. The instructions in the translation brief contain both linguistic and extralinguistic aspects, are formulated by the translation client/commissioner, and guide the translator in his/her enterprise: the (intended) text function(s), the profile of the TT addressees, the prospective time and place of text reception, the medium and motive for the production - reception of a translated text.

Again, the scheme of Nord's ST analysis, which is based on the NewRhetoric formula, comprises extratextual and intratextual factors, as well as the 
category of effect which involves both extratextual and intratextual co(n)texts. In this way, a more complete interpretation of the source text meaning in view of translation can be provided. Conversely, moving in a retrospective direction, evaluators may assess the accuracy and appropriateness of already existing translations making use of both dimensions of context.

The main difference between functionalist models in general and the other models in pragmatics/discourse analysis is that functionalist models 'courageously' and explicitly involve extra-textual incursions into the (source and) target socio-cultural context(s), referring to translations as occurring between linguacultures (Nord Translating as a Purposeful Activity). This kind of methodology positions functionalist approaches midway between pragmatic and socio-cultural approaches to translation studies. With the former they share in common the intratextual (linguistic, textual, generic, semiotic, etc.) perspective on the translated texts, while the socio-cultural aspects complete the picture by adding, besides the function fulfilled by texts in the target culture, the social agents (authors, translators, commissioners), the translation norms, the situationality of the source and target texts and other cultural aspects which go well beyond the concerns of strictly textual directions.

\section{Context in Cultural Approaches}

However, there are other directions in the discipline which assign an even more important place to extratextual contexts both in terms of source text interpretation and translation reception in the target culture. In one of their programmatic writings on the recent developments in the discipline, Translation, History and Culture (1990), Susan Bassnett and André Lefevere use the phrase "cultural turn" that they borrow from Mary Snell-Hornby (Translation Studies: an Integrated Approach) in order to signal the researchers' increasing interest in investigating translation as a phenomenon that could no longer be described and explained without an in-depth analysis of its cultural context. The cultural approaches to translation examine the links between translated literary texts and the cultures in which they are embedded as well as their relationship to (more recent) ongoing discourses in literary theory and criticism, philosophy, Cultural Studies and sociology. The researchers' multiple interests go from the position occupied by translations in various cultures to the way in which socio-cultural factors, poetics, ideology, politics, ethnic / gender identity, have shaped translations at different times and in different geographical areas. Many scholars have been equally concerned with the translators' social status, with their active intercultural role as gifted (re)creators of the source text for the target culture, of cultural mediators and negotiators of power relations. Although these studies mainly have in view literary works, many of them have informed non-literary texts as well. 
Within this broad socio-cultural background, one could further distinguish more specific contexts of investigation, some of them shared by several cultural orientations (cf. Dimitriu The Cultural Turn in Translation Studies). A very general one is the historical context. On the one hand, this sense of history has provided a dynamic and "realistic" background against which to explain the mechanisms of change in literary history, for which translations have been instrumental. In the highly formal polysystem theory, the historical dimension has helped scholars describe and justify the place and functions of translations at different times, in different cultures, and detect historically determined translation norms. Ideological orientations, such as the so-called "Manipulation School," as well as the contemporary orientations drawing on Cultural Studies, have shifted the emphasis of the historical perspective "towards a sense of greater relativity (...) as opposed to abstract, general rules that would always be valid" (Bassnett and Lefevere, Constructing Cultures, my emphasis). For example, to the post-colonial critics colonization is a historical fact, and itis the very reason for their discourse. The historical thrust equally enables translation scholars to analyse "peripheral" texts (written or translated by women, for example) and call into question the way in which translated texts became canonized.

Another specific socio-cultural context/framework of investigation has been the polysystem. Historically, it is rooted in Russian Formalism and is seen as a reaction against impressionistic or (mere) fact-finding criticism. Through this concept, the Israeli cultural scholar Itamar Even-Zohar describes the position and function of translations within a target culture. To the scholars of the School of Tel Aviv (Even Zohar and Gideon Toury) as well as to those of the Manipulation School (André Lefevere, Theo Hermans, Susan Bassnett, etc.), "(poly)system" has been a complex enough category to elaborate an ambitious historical and socio-cultural theory on how texts get to be translated in the target culture, on how they are translated, and what constraints may operate on the translators' choices.

The ideological context, which is part of the socio-cultural one, has been one of the most widely researched types of context. As already mentioned, (translation-oriented) critical discourse analysis has attempted to provide textual evidence of ideology, particularly in non-literary texts. But another obvious way of doing research in Translation Studies has been to analyse the extratextual political/ideological context and the impact it had (according to Lefevere through various forms of patronage, specialised institutions - of censorship, publishing houses, etc.) on translation policies or on the translated texts. Thus a lot of such ideological studies have been carried out for particular historical periods and particular target cultures. Their conclusions highlight some form of reader manipulation because of ideological constraints imposed on the 
translators or because of the translators' own ideology that they wanted to impose on their readers.

Starting in the late eighties, the shift of emphasis in Translation Studies from "literary studies" to Cultural Studies has become increasingly obvious. Nowadays many translation scholars work along post-structuralist, postmodernist and deconstructionist lines: Lawrence Venuti, Douglas Robinson, Rosemary Arrojo, (Brazil), Annie Brisset, Sherry Simon, Louise von Flotow, Tejaswini Niranjana, Gayatri Spivak (India), etc. Instead of analyzing translations through (poly)systems, some of these scholars seem to be more concerned about discussing their own ideological contexts and political agendas. Their research dwells on problems of cultural identity and the way it is constructed, on translators' visibility, hegemonic relations between cultures, hybrid cultures, resistive translation strategies, translation as recreation and transformation, ethnic/gender minorities, etc. This is, for instance, the case with postcolonial and gender-related translation discourses, two areas in which Translation and Cultural Studies have a lot to share.

\section{The Sociological Context}

Broadening the contexts of translation investigation has increasingly meant, particularly over the last two decades, foregrounding translational activity as a specific form of social practice. Just as linguistics has expanded, far beyond words and syntactic analysis, into textlinguistics, discourse analysis, pragmatics and cognitive grammar, the directions that are generally called "cultural" in Translation Studies have broadened their area of investigation so as to encompass studies with an increasingly sociological dimension. In an attempt to draw a (mainly methodological) line between the social and the cultural in Translation Studies, David Katan ("Translation as Intercultural Communication" 78) uses Hall's "iceberg model" dividing aspects of culture (the iceberg) into progressive layers in-between what is visible (i.e. above the waterline), what is semi-invisible and invisible (hidden); Katan reaches the conclusion that sociological aspects relate to fully visible practices which are located on the tip of the iceberg. Conversely, at the invisible bottom of the iceberg lie the core, the primary ethical values shared by a cultural community. Using the same model, Chesterman ("Questions in the Sociology of Translation" 12) concludes that, whereas cultural investigations of context focus on values, ideas and ideologies, analyses of sociological contexts emphasise people (especially translators) and their group behaviour in their professional milieu. Moreover, a number of keyconcepts in Translation Studies fall on borderline areas: for instance, norms have both social and cultural dimensions, discourse encompasses both texts and their social context, etc.

The perspective of translation as social practice had already been present in a number of directions in Translation Studies before scholars actually spoke 
of a sociological turn in the discipline or of a sociology of translation. It can be clearly found in skopos theory with its emphasis on the translator and on other agents involved in the translation process; similarly, and perhaps in an even more obvious manner it is noticeable in Justa Holz Mänttäri's theory of translatorial action that insists on the cooperation of the subjects involved in the social production of translation. Moreover, as has been repeatedly shown, Gideon Toury's "culturally-oriented" approach also has a social dimension, especially his theory of translation norms.

However, many clearly sociological topics are still under-researched and, consequently, under-theorised (cf. Wolf, "Sociology of translation" 337): training institutions, working conditions, professional institutions and their social role, questions of ethics in translation, (auto)biographies of translators, translation on the global market, sociopolitical aspects of translation, etc. At the same time, consistent translation-oriented sociological studies have been possible thanks to a number of far-reaching sociological models. One of these is Pierre Bourdieu's framework of investigation and, in particular, his key notions of field, habitus and capital, as well as his theories of symbolic forms. Scholars have analysed, for instance, within the category of field, the ways in which agents compete for positions of status and power (Hermans, Translation in Systems) or the roles played by economic factors, translators and publishers, marketing practices and book clubs in encouraging/discouraging the appearance of a new literary genre (Gouanvic, "The Stakes of Translation in Literary Fields"). Habitus, understood as "the basic psychological-emotional disposition of agents (in a field), including notions of role model, self-image and group identity" (Chesterman 13) is acquired by individuals through experience and socialisation in early life. It is the concept around which Daniel Simeoni organises, for instance, a translator-focused sociological study showing that, over the centuries, "translatorial habitus has contributed to the internalization of translators' submissive behavior, to their 'voluntary servitude,' which has had a decisive impact on the secondariness of their activity as such (in Wolf, "Sociology" 339).

In the 1990's André Lefevere incorporated into his translation theory Bourdieu's third key notion, that of cultural capital. In Lefevere's view, cultural capital refers to the information a person needs in any given society to belong to the "right circles" ("Translation Practice(s) and the Circulation of Cultural Capital" 41). Translation, among other factors, is directly responsible with the transmission, distribution and regulation of cultural capital not only between cultures, but also within one given culture.

Since the turn of the 21 st century, an increasing number of translation researchers working both in translation and interpreting (Anthony Pym, Jean Marc Gouanvic, Daniel Simeoni, Michaela Wolf, Moira Inghilleri, Miriam Shlesinger, Brian Mossop, etc.) have tried to apply the theories and 
methodological framework suggested by other sociologists and thinkers besides Bourdieu: Niklas Luhmann, Bernard Lahire, Martin Fuchs, Bruno Latour, etc.

Finally, special mention should be made of those sociologists/translation studies scholars who combine in their investigations the sociological and the globalizing contexts: in Translation and Globalisation, as well as in many other books and articles, Michael Cronin examines the ways in which relationships between translators have been affected by such radical changes to the world economy as the Internet, new technology, machine translation and the emergence of a global translation industry. Johan Heilbron ("Toward a Sociology of Translation") analyses the international flows of translated books between core and peripheral cultures, as part of a broader globalization process. $\mathrm{He}$ calls for more research on the social organization of different segments of the international translation market.

In conclusion, in view of its interdisciplinary character, Translation Studies has come to embrace, over successive decades, an increasingly wide and diverse range of contexts. So much so that the type(s) and dimensions of context could well be regarded as one of the distinguishing criteria between various orientations in Translation Studies.

However, this correlation between context and type of approach should not be seen in an excessively deterministic manner. There have been translation scholars whose theories of translation have actually exceeded the straitjacket of one type of context only. One such scholar has been Eugene A. Nida who, as early as the 1960's, and well ahead of his time, added a cultural component to his linguistic investigations and spoke of all kinds of contexts that need to be taken into consideration when interpreting meaning in translation:

Contexts need to be understood as influencing all structural levels of a text: phonological, lexical, grammatical, and historical, including events leading up to the production of a text, the ways in which a text has been interpreted in the past, and the evident concerns of those requiring and paying for a translation (Contexts in Translating, 9) .

$* * *$

Apart from its relevance to various directions of research in the discipline, context in its very broad sense as a "set of circumstances or facts that surround a particular event, situation, etc." (Random House Webster's College Dictionary) triggers an array of perspectives from which translations could be analysed.

Moreover, the articles published in this special issue of LINGUACULTURE are a good starting point in illustrating the idea that target texts could be approached from a myriad of angles of investigation: from adjustments of translations or downright adaptations to the theatrical and musical conventions in a particular culture, at a particular time in history, to translation as semiotic and rhetorical practice, incorporated in a literary work; 
from a novelist's self-translation in Canadian Quebec to the retranslation of a famous 20th century American author in post-communist Romania; from translation in a didactic/ecological context to various kinds of ironic translations in keeping with different literary genres and cultural contexts. It is this diversity of contexts that, paradoxically, assigns unity to this volume, generating equally diverse forms of translation - all discussed at length by the contributing authors.

A (translated) literary text may be interpreted in many different ways in different kinds of contexts, relating to genre, to time marked cultural and literary conventions and ideologies, target-culture diversity or the translator's own habitus and subjective data. In "Variations on Much Ado about Nothing: Beatrice and Benedick in Target-Language Adaptations" Marta Mateo examines various kinds of translations, adaptations and transpositions, the latter used in Törnqvist's acceptation of the term as referring to "systematic shifts in drama texts, between languages and/or media." Her exemplary case studies draw on the same source text, Shakespeare's Much Ado about Nothing, the Beatrice and Benedick-related plot in particular, and its multiple intralingual as well as interlingual and intersemiotic interpretations. Intralingually, within the British culture, the original text resilience appears to be a result of context variations such as the passage from page to stage, as well as historically marked interpretations - by stage directors and literary critics - of the comic and dark aspects of the Beatrice and Benedick relationship as well as of gender and power issues in general. The (broad) context offered by the second case study is that of Spanish culture. Jacinto Benavente' $\mathrm{s}$ adaptation of the Beatrice and Benedick plot as Los favoritos (1892) is significantly different from the Shakespearean text in terms of play length, number of characters, the two contrasted couples, plot and, last but not least, the (lighter) general tone of the play. Ideologically, Los favoritos is shown to reflect the author's concern with gender issues, women's predicament in particular. The Spanish adaptation is thus a culturally marked, context-dictated, more radical transformation of Much Ado. The last case study deals with the English play's transposition into Hector Berlioz's Béatrice et Bénédict (1862); this multimodal text (Snell-Hornby 2006) entails a combination of passages translated into French for the libretto with 19th century (French) opera-related conventions. While highlighting the complex relationship between the English source and its intersemiotic translation, Mateo reaches the interesting conclusion that many parts of the libretto are, in fact, accurate translations of the Shakespearian text, whereas the function of the musical code is to convey the characters' feelings and emotions or reveal their importance. In the author's view, all these illustrations ultimately foreground the temporariness, malleability and resilience of dramatic texts that can be adjusted to an endless number of contexts.

Through some kind of reversal of perspective, from translated author Shakespeare becomes ekphrastic translator in Pia Brînzeu's article, which 
analyses in detail the inter-semiotic translation (Jakobson)/transposition (Törnqvist) undertaken in The Rape of Lucrece by the character herself, whose perspective (and "voice") is occasionally joined by the author's. One (intratextual, embedded) context in this case is a wall-painting illustrating a scene from the Trojan War. It is described through a unique piece of ekphrastic translation, in which painting and poetry are harmoniously blended. A second (extratextual) context is that of Renaissance, as ekphrasis is both a Renaissancerelated rhetorical convention, "guiding the reader's interpretation of the poem," and a powerful manner of conveying "Renaissance perceptions of rape, body, gender issues, and history," with a strong impact on the readers of the poem.

To Sara Laviosa the contexts of (teaching and learning) translation in our global world are manifold. One of them is the ecological didactic perspective provided by van Lier and Kramsch, which encourages the study of language seen as "relations (of thought, action, power), rather than [...] objects (words, sentences, rules)" as well as the creation of multilingual subjects endowed with symbolic, translingual and transcultural competence. This theoretical context is further completed by the introduction of Maria Tymoczko's concept of "holistic cultural translation" that allows for the incorporation of material culture within broader symbolical frameworks. In this way, language and translation can be simultaneously taught starting from similar premises and sharing in common several objectives and competences to develop.

A second 'real' kind of context is offered by Laviosa's personal experience of classroom teaching and distance learning involving Italian and English teacher trainees. The didactic tasks (the analysis of several scenes and their translation via subtitling) are based on a multilingual film, La stella che non c'è/The Missing Star (directed by Gianni Amelio, 2006), the main topic of which is the (Italian) main character's journey to China accompanied by his Chinese interpreter and cultural mediator. This travel of both self-discovery and discovery of the other in the transcultural world of the film turns out to be highly formative and enriching for the trainees as well: in a pedagogic context of collaborative learning, carried out in a multilingual classroom, the trainees develop their own symbolic competence that helps them better understand cultural variety and act accordingly. Finally, and in line with Tymoczko's claims, this experiment triggers comparisons with the participants' own culture heightening their self-reflexivity.

Self-reflexivity is also what Daniel Gagnon's article is about. The author writes - and translates his works - in a particular geo-political context: that of his native Canada, a multicultural country with two official languages. This is why, in this particular setting, issues of bilingual writing or selftranslation acquire a different significance and a new motivation. Gagnon's own experience of writing two novels in English (My Husband the Doctor and The Marriageable Daughter) at a time (1984 and 1989, respectively) when he was 
"far from bilingual," at least in a narrow acceptation of this term, is justified by his (perhaps paradoxical to outsiders) perception of English as a "language of liberation" from two equally 'oppressive' varieties of French: the Québécois French ('joual') and the Parisian 'imperial[istic]' alternative. To this the author adds, later on in the article, a series of "painful affective undertones" of the French language associated, as it was, "with the language of childhood experiences."

The development of Gagnon's own writing, and the meta-texts devoted to it involve a series of departures from the diasporic or post-colonial paradigms. Thus, the author regards two of his novels, initially written in English, as instances of "cross-writing" rather than bilingual writing, drawing on what he calls a "cross-cultural communicative aesthetics." This newly coined notion combines the writer's more general habitus with his more specific personal experience of letter writing to native speakers of English, with whom he shared in common a feeling of (artistic) solidarity. The same concepts are equally relevant when it comes to analyzing the two (self-) translations into French of the English novels, i. e. Mon mari le docteur (1986) and La fille à marier (1985), respectively, the latter a winner of Prix Molson de l'Académie des lettres du Québec. Once again, whereas bilingual writing would have encouraged the reading of the two translated novels "as one text," cross-writing makes it possible to individualize the reading of each of the two versions in its own cultural context, and also in keeping with particular historical moments, mainly the Canada-Québec relations. Finally, if applied to translation, the notion of communicative aesthetics implies a return to the target language (French) literary norms, resulting in a more fluent, less disruptive (translated) text. A final general conclusion of the article is that both processes of creating original works and (self-) translating them in a Canadian context entail complex linguistic and cross-cultural operations which bear ideological significance and leave their imprints on the writers' and translators' style.

Various extra and intratextual contexts of writing and publishing literary translations are also discussed in George Volceanov's article, an instance of translation (self)criticism undertaken from a comparative stance. The significant differences between the two Romanian versions of Truman Capote's Other Voices, Other Rooms are firstly justified by ideological factors. The first translation that came out in the communist period (1978) deliberately eludes or attenuates - via a vigilant system of censorship and the translator's skillful selfcensorship - all those elements in the original relating to the taboo topic of homosexuality - totally unacceptable according to communist moral standards. Several such ethically problematic passages are discussed and compared with the uncensored translation that came out in 2015 undertaken by Volceanov himself. A second (subtler and more difficult to grasp) kind of context is generated by what is usually called, for lack of more refined investigations at 
this level, "the translator's subjectivity," by his/her stylistic idiosyncrasies and personal approach to different kinds of translation problems in the source text. The result of this new series of comparative analyses of the communist translation vs. the post-communist one is a complex portrayal of the first translator of the novel, the well-reputed poet Mircea Ivănescu, who had also translated from other famous British and American novelists besides Capote, e.g. Scott Fitzgerald, Joyce, Faulkner, etc.

Volceanov's detailed investigations of Capote's text as rendered by Ivănescu - and himself - reveal the former's idiosyncrasies as a translator, and turn many of the analyses into downright critiques. For instance, Ivănescu's tendency to take too many liberties with the source text, and "embellish arid passages," may, on a positive note, contribute to the textual fluency and expressiveness of the translation; on the other hand, though, Ivănescu's frequent mistranslations, a result of carelessness combined with his poetic/ whimsical choices, as well as with his redundancies are shown, by means of textual evidence, to have been detrimental to a 'fair' reception of Capote's text in the communist period.

All these reasons justify Volceanov's retranslation of the novel in a different socio-cultural, ideological and literary receptive context. The author himself sees his article as vivid proof of the "feuds" that have always existed between older and more recent translations. He also regards it as yet another instance of reconsideration of canonical literary values, of translations and their authors.

Oana Babîi approaches the more specific contexts conditioning the translation of irony, in an attempt to establish a network of correlations between types of irony, literary genres in which they may be found and strategies that are used for their translation; she also tries to find out whether culture-related factors may have a bearing on the translators' choices. Babîi's highly detailed taxonomy of irony is a synthesis of the most significant elements that are present in each classification (D. C. Muecke, Norman Knox, W. C. Booth, Claire Colebrook, etc.), 'filtered,' nevertheless, and reorganized by the author so as to make it meaningful for translation-related investigations. Throughout her extensive analyses, Babii makes use of a parallel corpus of literary texts belonging to famous British ironists - Swift, Wilde, Huxley and Lodge - and their Romanian translations, as well as of Marta Mateo's classification of strategies for translating ironic texts. Her statistics show that the most widely used translation strategies are the "equivalent effect" ones, closely followed by literal translations. Moreover, according to the suggested taxonomy, the type of irony which is the most difficult to translate is verbal irony which may be overlooked, hence misinterpreted, even by the readers of the original texts and by translators themselves. In terms of literary genres, Babîi's studies show that it is novels that contain more intricate types of irony, whereas overt, more accessible forms 
prevail in plays. Finally, culture-specific factors may act as obstacles to interpreting irony and the author's (tentative and arguable) suggestion is their explanation through footnotes, whenever possible, especially if culture-marked ironic instances are present in novels. In this way, the translator's voice becomes only extratextually audible and does not interfere with the implicitation processes that irony involves.

In an article on contexts in translation, Melby and Foster aptly notice that "one could study context in translation either for the purpose of analyzing existing translations or for the purpose of improving the production of new translations" (3). Considered from this angle, the articles in this issue, full of variety as they are, and bringing each new insights into the study of context are all retrospective. Prospective kinds of studies, with didactic objectives in mind, focusing on translated texts created with the appropriate contexts of communication in mind, would add further layers of significance to this allimportant multifaceted concept.

\section{Works Cited}

Baker, Mona. In Other Words.A Coursebook on Translation. London/New York: Routledge, 1992. Print.

Bassnett, Susan and André Lefevere (eds). Translation, History and Culture. London and New York:Pinter, 1990. Print.

Bassnett, Susan and André Lefevere. Constructing Cultures. Clevedon: Multilingual Matters, 1998. Print.

Benson, Morton, Evelyn Benson and Robert Ilson. The BBI Dictionary of English Word Combinations. Amsterdam/Philadelphia: John Benjamins, 1997. Print.

Catford, J. C. A Linguistic Theory of Translation, London/Oxford: Oxford University Press, 1965. Print.

Chesterman, Andrew. "Questions in the Sociology of Translation.”Translation Studies at the Interface of Disciplines.Eds. João Ferreira Duarte, Alexandra Assis Rosa and Teresa Seruya. 9-27. Amsterdam/ Philadelphia: John Benjamins, 2006. Print.

Cronin, Michael. Translation and Globalization. London/New York: Routledge, 2003. Print.

Derrida, Jacques. Margins of Philosophy.Chicago: University of Chicago Press, 1984. Print.

Dimitriu, Rodica. The Cultural Turn in Translation Studies. Iaşi: Institutul European, 2006. Print.

Gouanvic, Jean Marc. "The Stakes of Translation in Literary Fields." Across Languages and Cultures. 3.2 (2002): 159-168. Print.

Hatim, Basil and Ian Mason. Discourse and the Translator. London/New York: Longman, 1990. Print.

Hatim, Basil and Ian Mason. The Translator as Communicator. London/New York: Routledge, 1997. Print.

Hermans, Theo. Translation in Systems. Manchester: St. Jerome Publishing, 1999. Print. Heilbron, Johan. "Toward a Sociology of Translation: Book Translations as a 
Cultural World-System.”European Journal of Social Theory. 2. 4 (1999): 429444. Print.

Hoey, Michael. Lexical Priming.A new theory of words and language.London/New York: Routledge, 2005. Print.

Holz Mänttäri, Justa. Translatorisches Handeln.Helsinki : Suomalainen Tiedeakatemia, 1984. Print.

House, Juliane. Translation Quality Assessment: A Model Revisited. Tübingen: Gunter Narr, 1997. Print.

House, Juliane."Text and Context in Translation.” Journal of Pragmatics. 38.3 (2006): 338-358. Print.

Jakobson, Roman. "On Linguistic Aspects of Translation."Theories of Translation: an Anthology of Essays from Dryden to Derrida. Eds.

Rainer Schulte and John Biguenet. 232-239. Chicago /London: The University of Chicago Press. Print.

Katan, David. "Translation as Intercultural Communication."The Routledge Companion to Translation Studies.Ed. Jeremy Munday.74-92. London/New York: Routledge, 2009. Print.

Lefevere, André. "Translation Practice(s) and the Circulation of Cultural Capital. Some Aeneids in English."Constructing Cultures. Eds. Susan Bassnett and André Lefevere. 25-40. Clevedon:Multilingual Matters, 1998. Print.

Melby, Alan K. and Christopher Foster. "Context in translation: Definition, access and teamwork."Translation \& Interpreting2.2 (2010): 1-15. E- journal.

Munday, Jeremy. Introducing Translation Studies. London/New York: Routledge, 2008. Print.

Munday, Jeremy. "Translation and Ideology.A Textual Approach.”The Translator. 13.2 (2007): 195-217. Print.

Munday, Jeremy (ed.). The Routledge Companion to Translation Studies. London/New York: Routledge.2009. Print.

Neubert, Albrecht and Gregory M. Shreve.Translation as Text. Kent, Ohio: University of Kent OhioPress, 1992. Print.

Neubert, Albrecht. "Textlinguistics of Translation: the Textual Approach."Translation Horizons- Beyondthe Boundaries of Translation Spectrum.Translation Perspectives IX.Ed. Marilyn Gaddis Rose.87-106. State University of New York at Binghamton: Center for Research in Translation, 1996. Print.

Newmark, Peter. A Textbook of Translation. London: Prentice Hall, 1988. Print.

Newmark, Peter. About Translation.Clevedon: Multilingual Matters, 1991. Print.

Nida, Eugene A. Toward a Science of Translating. Leiden: E. J. Brill, 1964. Print.

Nida, Eugene A. Contexts in Translating. Amsterdam/Philadelphia: John Benjamins, 2001. Print.

Nord, Christiane. Text Analysis in Translation. Amsterdam/Atlanta: Rodopi, 1991. Print.

Nord, Christiane. Translating as a Purposeful Activity. Manchester: St. Jerome,1997. Print. Random House Webster's College Dictionary 2010. Print.

Rogers, Margaret. "Translating Terms in Text: Holding on to Some Slippery Customers."Word, Text,Translation. Eds. Gunilla Anderman and Margaret Rogers. 104-118. Clevedon: MultilingualMatters, 1999. Print. 
Schäffner, Christina. "Functionalist Approaches." Eds. Mona Baker and Gabriela Saldanha. 115-121.Routledge Encyclopedia of Translation Studies.London/New York: Routledge, 2009. Print.

Séguinot, Candace."Translation Theory, Translating Theory and the Sentence."Word, Text, Translation.Eds. Gunilla Anderman and Margaret Rogers. 84-94. Clevedon: Multilingual Matters, 1999. Print.

Simeoni, Daniel. "The Pivotal Status of the Translator's Habitus.” Target 10.1 (1998): 1-39. Print.

Snell-Hornby, Mary. Translation Studies: an Integrated Approach, Amsterdam / Philadelphia: JohnBenjamins, 1988. Print.

Snell-Hornby, Mary. The Turns of Translation Studies, Amsterdam/Philadelphia: John Benjamins, 2006. Print.

Trosborg, Anna (ed.). Text Typology and Translation. Amsterdam/Philadelphia:John Benjamins, 1997. Print.

Vermeer, Hans and Katharina Reiss.Towards a General Theory of Translational Action.Transl.Christiane Nord.London/New York: Routledge, 2013. Print.

Wolf, Michaela. "Sociology of translation."Handbook of Translation Studies. Eds. Yves Gambier and Luc Van Doorslaer. 337-343. Amsterdam/Philadelphia: John Benjamins, 2010. Print. 